\title{
A name in vain?
}

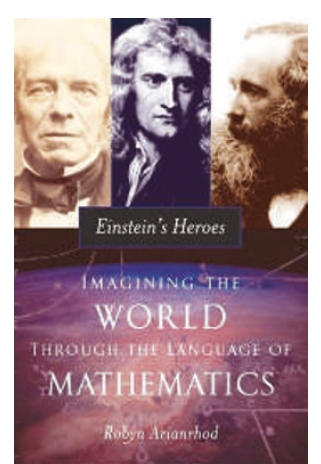

Einstein has dominated his subject more than any other scientist since the advent of mass media. Nowhere is this more evident than in the titles of popular science books. It is now a favourite ploy of their publishers to give a book a title that tells us not what it is about but what it has (or might have) to do with Einstein: The Einstein Factor; What Einstein told his barber; Sex, Drugs, Einstein and Elves;... What next?

Taken at face value, Einstein's Heroes is a promising title. Might this be a longoverdue homage to Hendrik Lorentz and Willard Gibbs? Einstein held these two theoreticians in extremely high regard, but they are almost unknown outside academia and widely undervalued even by physicists. No, the book's cover illustration indicates that the author, the Australian writer Robyn Arianrhod, is giving yet another account of Einstein's debt to Newton, Faraday and Maxwell. The prominently presented subtitle suggests, however, that she also has the more interesting and ambitious aim of explaining how the world can be imagined "through the language of mathematics".

Arianrhod is an infectiously enthusiastic writer, keen for her audience both to admire Einstein's heroes and to understand their contributions to fundamental mathematical physics. She leavens her account with a good deal of recycled history, including the now-inevitable quote from Newton: "If I have seen far, it is because I have stood on the shoulders of giants". It is time for a moratorium on these hoary words, unless they are accompanied by a reminder that Newton was using a centuries-old quotation. It is engraved in a window of the cathedral at Chartres.

In the most original parts of Einstein's Heroes, Arianrhod works hard to describe intelligibly the emergence of the modern concept of the field in physics. As usual in this type of book, she simplistically gives almost all the credit to Faraday, for having the essential idea, and to Maxwell, for bringing it to mathematical fruition. Einstein, as she rightly says, was stimulated to develop his relativity theory by Maxwell's equations of electromagnetism, although she mars her account with several gaffes, including the ludicrous assertion that Maxwell's theory of electricity and magnetism is "on a much subtler scale" than Einstein's theory of gravity.

By the end of the book, it is clear that Arianrhod's primary goal is to praise Maxwell's life and emphasize the importance of his work. By all accounts, he was not only a brilliant scientist but also a delightful and blameless man, which is why so many accounts of his life are hagiographies. Arianrhod does not avoid this trap. Worse, she loses sight of her audience, going into detail that will baffle some undergraduates, let alone readers who have little basic science or mathematics.

This brave and well-intended book ultimately fails because it tries to address too many things, and does none of them especially well. Arianrhod would have done better to write a popular biography of Maxwell that underlines his huge influence on modern physics. She would do a superb job of that. One can't help suspecting that she has been pressed to compromise by relating her favourite subject to Einstein, who has little more than a walk-on part - except apparently to ensure the book's marketability.

It is striking that although Einstein's public prestige shows no sign of abating, the popularity of his subject with young students seems to fall further every year. How long will it be before some oleaginous marketing consultant proclaims that physicists should bow to the inevitable and rebrand their subject 'Einsteinism'?

\section{Graham Farmelo}

Graham Farmelo is a senior research fellow at the Science Museum, London SW7 2DD, UK.

\section{New in paperback}

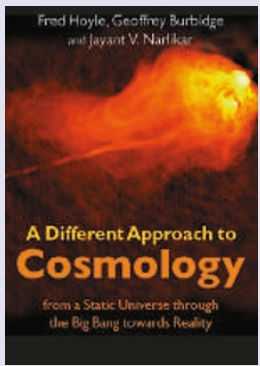

A Different Approach to Cosmology by Fred Hoyle, Geoffrey Burbidge \& Jayant V. Narlikar Cambridge Univ. Press: 2005. 369pp. $\$ 50$

A challenge to the conventional account, Hoyle, Burbidge and Narlikar present their famously controversial alternative to the hot Big Bang model.

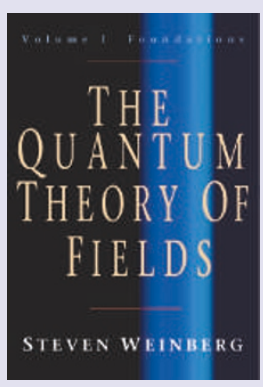

The Quantum Theory of Fields by Steven Weinberg Cambridge Univ. Press: 2005. 3 vols. \$45 each.

This three-volume series moves from the historical foundations of quantum field theory, to its modern applications, to supersymmetry - which, says Weinberg in the preface, "has the quality of uniqueness that we search for in fundamental physical theories". 